\title{
Does inflammation mediate the effect of pessimism on coronary heart disease? A ten-year follow-up study
}

\section{Mikko Pänkäläinen ( $\square$ mikko.pankalainen@phhyky.fi )}

Päijät-Häme Central Hospital, University of Tampere https://orcid.org/0000-0002-8340-0928

\section{Tuomas Kerola}

Paijat-Hameen keskussairaala

\section{Olli Kampman}

Tampereen Yliopisto

Markku Kauppi

Paijat-Hameen koulutuskonserni Tieto- ja kirjastopalvelut

\section{Hannu Sarkkinen}

Fimlab Laboratoriot Oy

\section{Erja Lappalainen}

Paijat-Hameen keskussairaala

Jukka Hintikka

Tampereen Yliopisto

\section{Research article}

Keywords: Pessimism, optimism, coronary heart disease, Life Orientation Test - Revised, C-reactive protein, low-level inflammation

Posted Date: June 9th, 2020

DOI: https://doi.org/10.21203/rs.3.rs-32636/v1

License: (c) (i) This work is licensed under a Creative Commons Attribution 4.0 International License. Read Full License 


\section{Abstract}

\section{Background}

Coronary heart disease (CHD) is a notable cause of mortality worldwide. Psychosocial factors have been confirmed to have an effect on the risk for cardiovascular diseases and gradually pessimism has also been recognized as a risk factor for CHD. The mechanism by which pessimism elevates the risk for CHD is unknown. According to one theory pessimism increases low-level inflammation and an elevated inflammation level has in turn been connected with an increased risk for CHD. However, the theory of inflammation working as a mediator between pessimism and the onset of $\mathrm{CHD}$ has yet to be proven.

\section{Methods}

We conducted a ten-year prospective cohort study on a regional sample of three cohorts aged $52-56$, $62-66$, and $72-76$ years at baseline $(\mathrm{N}=2,815)$. A revised version of the Life Orientation Test was used at baseline to define the levels of dispositional optimism and pessimism. The level of inflammation was determined by measuring the level of C-reactive protein using high sensitivity assays. These results and the data of new cases of CHD during the follow-up were used in the statistical analyses. The mediation effect of C-reactive protein between pessimism and new cases of CHD was calculated.

\section{Results}

Study subjects with a new case of CHD during the follow-up were more pessimistic and had higher Creactive protein values at baseline than other study subjects. The pessimism score and C-reactive protein value correlated statistically significantly. We found that the connection between pessimism and developing CHD during the study period was partially mediated via the level of C-reactive protein.

\section{Conclusion}

Pessimism seemed to be a substantial risk factor for developing CHD. Pessimism was connected with the level of inflammation. The theory that elevated inflammation level mediates indirectly the connection between pessimism and the risk for CHD could be proved partially. Consequently, other mediators between pessimism and $\mathrm{CHD}$ remain unclear.

\section{Background}

Despite steady decreases in CHD mortality, CHD is still the cause of one in every five deaths in Europe [1]. It is obvious that increased knowledge about the treatment, aetiology, and the mechanisms of $\mathrm{CHD}$ are needed in order to improve the prevention of $\mathrm{CHD}$ and $\mathrm{CHD}$-related deaths. 
Psychosocial factors have gradually been recognized as playing a part in the aetiology of CHD, and it has been found that psychosocial stress, depression, and pessimism, for example, are strongly connected with an elevated risk of developing CHD; furthermore, they seem to worsen the outcomes of the treatment in situations when CHD is already present [2], [3], [4], [5], [6]. However, the mechanism of this connection between psychosocial risk factors and the course of $\mathrm{CHD}$ is still unclear.

Inflammation plays a part in many phases of the atherosclerotic process, from endothelial dysfunction to plaque build-up [7]. There are many biomarkers indicating the inflammation process, of which C-reactive protein (CRP), when measured with high-sensitivity assays (hs-CRP), seems to be the most reliable and the most useful method [7], [8].

In our earlier studies on this population, we discovered that there is a clear connection between pessimism and CHD [4], [9]. Although some earlier studies have connected markers of inflammation with measures of optimism/pessimism, there is no previous data about the inflammation working as a possible mediator between adequately measured dispositional optimism and CHD. [10], [11], [12], [13], [14].

Hence, we conducted this ten-year follow-up study to assess whether optimism and/or pessimism affects the risk of developing CHD via inflammation. Our hypothesis was that pessimism and elevated level of inflammation are associated with each other, and this connection could mediate the effect of pessimism on developing CHD.

\section{Methods}

Study Population

Our study is a part of the GOAL (Good Ageing in Lahti region) study. The GOAL study was conducted in the region of Lahti, Finland, and its aim was to discover ways to improve the health and well-being of the local ageing population in the future. The GOAL study started in 2002 when stratified (age, sex, municipality) random samples of men and women born in 
1926-30, 1936-40, and 1946-50 were drawn from the population register of all 14

municipalities in the Lahti region. A total of 4,272 subjects were invited to the study, and $2,815(66 \%)$ of them agreed to participate. For the purposes of the present study we excluded participants with baseline $\mathrm{CHD}(\mathrm{N}=274)$. Additionally, participants were excluded due to incomplete follow-up/missing co-variate $(\mathrm{N}=591)$ or death not related to $\mathrm{CHD}(\mathrm{N}=393)$ forming final study population of 1,557 subjects.

Covariate ascertainment

The study subjects were personally interviewed at the beginning of the study in 2002 , and the follow-up of the study subjects lasted for ten years. At baseline in 2002, the study subjects filled in questionnaires concerning their current life status and lifestyle: the use of alcohol, smoking habits, health, possible medications, and the level of physical exercise were documented.

Study subjects were measured for height and weight, and their body mass indexes (BMI) were calculated. The blood pressure of the study subjects was measured three times and the average was documented. Venous blood samples were taken with standardized methods and blood glucose, blood total and high-density lipoprotein (HDL) cholesterol were determined. The blood samples were stored at $-70^{\circ} \mathrm{C}$ and the level of high sensitivity C-reactive protein (hs-CRP) for each study subject was determined in 2016 from the frozen samples.

The study subjects were asked whether they had been diagnosed with CHD by a doctor. The alcohol consumption habits were determined by using the Alcohol Use Disorders Identification Test - Consumption (AUDIT-C) questionnaire, which is an abbreviated but as reliable as the original 10-item version of AUDIT and includes the three items on alcohol consumption [15], [16], [17], [18].

The study subjects were asked to fill in the revised version of the Life Orientation Test (LOT-R) in order to measure their dispositional optimism and pessimism, two separate measures in 
the present study. LOT-R is a re-evaluated version of the Life Orientation Test (LOT), which was initially developed in the mid-1980 s to assess the effects of dispositional optimism on the self-regulation of behaviour in a wide variety of domains, some of them health-related [19]. The revision and re-evaluation was made by Scheier, Carver, and Bridges to focus its item content more closely on the subject's expectations of the future [20].

LOT-R includes four fillers and six actual statements, of which three are worded positively (e.g. 'In uncertain times, I usually expect the best') and three are worded negatively (e.g. 'If something can go wrong for me, it will'), indicating optimism and pessimism, respectively. The respondents are asked to estimate how much they agree with the statements in general on a scale of 0 ('I disagree a lot') to 4 ('I agree a lot'). A higher score refers to greater optimism or greater pessimism depending on the statement.

In this study we used separate subscale scores for the optimistically and pessimistically oriented questions. The subscales were named 'optimism' and 'pessimism', respectively. Outcome ascertainment

At the end of the follow-up period in 2012, the study subjects were asked in the interview if they had been diagnosed with CHD by a doctor since the beginning of the study. The causes of death of those study subjects who had died during the follow-up were obtained from the statistics of The National Institute for Health and Welfare (THL).

Statistical analyses

In the statistical analyses, we used the Chi-squared test for categorical variables. To compare continuous variables, we used the nonparametric Mann-Whitney U test. Spearman's correlation coefficient (rho) was calculated for an association between pessimism and hs-CRP at baseline. Fully adjusted logistic regression models were calculated. In the final step, we analysed whether there were indirect mediation effects between 
pessimism and new cases of CHD due to the level of hs-CRP. These effects were calculated using equations by MacKinnon and Dwyer [21], which are based on Baron and Kenny's four steps in establishing mediation [22]. The Sobel test was used to assess the statistical significance of indirect mediation effects. For analyses considering hs-CRP as a continuous variable, we performed a logarithm transformation due to the skewed distribution of hs-CRP.

\section{Results}

There were 200 new cases of CHD (69 CHD deaths and 131 cases reported in the interview by the study subjects) during the follow-up of 10 years.

Those who got CHD during the 10-year study period were at baseline older, more often men, had higher systolic blood pressure, body mass index, blood glucose and hs-CRP, smoked more often, consumed less alcohol, performed less physical exercise and were more pessimistic than the others (Tables $1 \& 2$ ). The pessimism score and C-reactive protein value correlated weakly but statistically significantly (rho $0.119, p<0.01$ ). 
Table 1

Baseline characteristics and incidence of CHD during the 10-year follow-up period

\begin{tabular}{|c|c|c|c|c|c|}
\hline \multirow[t]{4}{*}{$\begin{array}{l}\text { Risk factors at } \\
\text { baseline (2002) }\end{array}$} & \multicolumn{4}{|c|}{$\begin{array}{l}\text { A new case of coronary heart disease during the 10-year } \\
\text { follow up (2002-2012) }\end{array}$} & \multirow{4}{*}{$\begin{array}{l}\text { Mann-Whitney } \\
\text { UTest } \\
\\
\text { p-value }\end{array}$} \\
\hline & \multirow{2}{*}{\multicolumn{2}{|c|}{$\begin{array}{l}\text { Yes } \\
N=200\end{array}$}} & \multirow{2}{*}{\multicolumn{2}{|c|}{$\begin{array}{l}\text { No } \\
N=1,357\end{array}$}} & \\
\hline & & & & & \\
\hline & Mean & SD & Mean & SD & \\
\hline Optimism score & 8.45 & 2.05 & 8.39 & 2.07 & 0.69 \\
\hline Pessimism score & 4.56 & 2.53 & 3.47 & 2.55 & $<0.001$ \\
\hline B-glucose (mmol/L) & 6.11 & 1.47 & 5.51 & 0.88 & $<0.001$ \\
\hline $\begin{array}{l}\text { Total cholesterol } \\
(\mathrm{mmol} / \mathrm{L})\end{array}$ & 5.85 & 1.13 & 5.87 & 1.01 & 0.91 \\
\hline $\begin{array}{l}\text { HDL cholesterol } \\
(\mathrm{mmol} / \mathrm{L})\end{array}$ & 1.38 & 0.40 & 1.57 & 0.43 & $<0.001$ \\
\hline Age (years) & 66.7 & 7.5 & 60.7 & 7.2 & $<0.001$ \\
\hline Systolic BP (mmHg) & 150.0 & 19.6 & 143.4 & 17.8 & $<0.001$ \\
\hline Diastolic BP (mmHg) & 85.5 & 10.0 & 86.7 & 9.4 & 0.09 \\
\hline $\begin{array}{l}\text { Body mass index } \\
\left(\mathrm{kg} / \mathrm{m}^{2}\right)\end{array}$ & 29.2 & 5.1 & 27.4 & 4.4 & $<0.001$ \\
\hline $\mathrm{Hs}$-CRP & 3.34 & 6.65 & 2.26 & 3.61 & $<0.001$ \\
\hline AUDIT-C & 2.55 & 2.43 & 2.81 & 2.23 & 0.025 \\
\hline
\end{tabular}

$\mathrm{SD}=$ standard deviation; $\mathrm{HDL}$ = high density lipoprotein; $\mathrm{BP}=$ blood pressure; Hs-CRP = high sensitivity Creactive protein; AUDIT-C = Alcohol Use Disorders Identification Test - Consumption 
Table 2

Baseline characteristics and incidence of CHD during the 10-year follow-up period.

\begin{tabular}{|c|c|c|c|c|c|c|}
\hline & $\begin{array}{l}\text { A ne } \\
\text { durit } \\
\text { the }\end{array}$ & of cc & $\begin{array}{l}\text { y hea } \\
2002\end{array}$ & $\begin{array}{l}\text { ease } \\
\text { 2) }\end{array}$ & $\begin{array}{l}\text { Chi square } \\
\text { value }\end{array}$ & $p$ value \\
\hline & Yes & & No & & & \\
\hline & $N=2$ & & $N=1$ & & & \\
\hline & $\mathbf{N}$ & $\%$ & $\mathbf{N}$ & $\%$ & & \\
\hline Gender & 123 & 17.2 & 592 & 82.8 & 23.43 & $<0.001$ \\
\hline Men $(N=715)$ & 77 & 9.1 & 765 & 90.9 & & \\
\hline Women $(\mathrm{N}=842)$ & & & & & & \\
\hline Regular physical & 102 & 11.3 & 798 & 88.7 & 4.36 & 0.04 \\
\hline Yes $(N=900)$ & 98 & 14.9 & 559 & 85.1 & & \\
\hline No $(N=657)$ & & & & & & \\
\hline Daily smoking & 101 & 16.9 & 497 & 83.1 & 14.19 & $<0.001$ \\
\hline Yes $(N=598)$ & 99 & 10.3 & 860 & 89.7 & & \\
\hline No $(N=959)$ & & & & & & \\
\hline
\end{tabular}

Regular physical exercise $=$ those who exercised for at least 30 minutes per session at least twice a week. Daily smoker $=$ those who had smoked daily at least a year during their lifetime.

In the fully adjusted logistic regression (Table 3) without pessimism and hs-CRP in the model, higher age, higher blood glucose, lower HDL cholesterol, daily smoking, and lack of regular physical exercise - but not gender, systolic blood pressure, alcohol use, or body mass index associated with the risk of developing CHD during the follow-up period (Model I). When pessimism and hs-CRP were included in the model, the result remained essentially the same (Model II). However, in this model the risk for developing CHD associated with male gender but no more with lack of regular physical exercise. Both pessimism and higher hs-CRP associated independently with the risk of having a new case of CHD during the follow-up. A statistically significant indirect mediation effect was found between pessimism and 
developing CHD via the level of hs-CRP (28.5\% of the connection between pessimism and the incidence of $\mathrm{CHD}, \mathrm{Z}=3.03, \mathrm{p}=0.001$ ) during the 10 -year study period.

Table 3

Baseline characteristics and the risk of developing CHD during the 10-year followup.

\begin{tabular}{|lll|}
\hline & Model I & Model II \\
\hline Gender (males/females) & OR $(95 \% \mathrm{Cl})$ & OR $(95 \% \mathrm{Cl})$ \\
Age (years) & $1.49(0.99-2.23)$ & $1.59(1.05-2.40)$ \\
Systolic blood pressure (mmHg) & $1.12(1.09-1.14)$ & $1.11(1.08-1.14)$ \\
Body mass index (kg/m2) & $1.01(1.00-1.02)$ & $1.01(0.98-1.02)$ \\
B-glucose (mmol/L) & $1.03(1.00-1.07)$ & $1.02(0.98-1.06)$ \\
HDL cholesterol (mmol/L) & $1.29(1.12-1.48)$ & $1.28(1.11-1.47)$ \\
Daily smoking (yes/no) & $0.51(0.32-0.84)$ & $0.53(0.33-0.86)$ \\
AUDIT-C score & $2.19(1.51-3.17)$ & $2.10(1.46-3.05)$ \\
Regular physical exercise (yes/no) & $0.93(0.86-1.02)$ & $0.93(0.85-1.01)$ \\
Pessimism score & $\ldots .$. & $0.74(0.53-1.03)$ \\
High-sensitivity CRP (In transformation) & $\ldots .$. & $1.10(1.04-1.17)$ \\
\hline
\end{tabular}

Fully adjusted logistic regression models: Model I is without pessimism score and hs-CRP in the model. Model II includes pessimism score and hs-CRP in the model.

\section{Discussion}

The main finding of this study was that higher level of pessimism predicted the incidence of CHD after adjusting to other predictors of CHD. Significant proportion of this effect was

mediated by increased inflammation among those with more pessimism.

We are reporting for the first time the possible mediator effect of hs-CRP in the context of pessimism and cardiovascular risk. Pessimism was an independent predictor of higher incidence of CHD in both models applied. This finding is in line with a large body of evidence connecting pessimism and higher incidence of CHD [4], [23], [24], [25], [26]. Hs-CRP, a marker 
of inflammation, and a known predictor of cardiovascular disease, was also connected to incidence of $\mathrm{CHD}$ in the present population. According to our analysis hs-CRP mediated nearly $30 \%$ of the pessimism related effect on $\mathrm{CHD}$.

Positive affective states have been connected with lower hs-CRP levels [27] while increasing severity of depression seems to correlate with an elevated hs-CRP level [28], [29]. In a research derived from the Heart and Soul Study, the connections between depression and inflammation, between depression and CHD, and between inflammation and CHD were affirmed. Contrary to our positive findings about the inflammation mediating the effect of psychosocial risk factor on the incidence of CHD, investigators of Heart and Soul Study found no evidence of inflammation operating as a mediator between depression and CHD [30]. Parallel findings have also been made about optimism. A study about the optimistic perception of one's CVD risk found lower rates of adverse effects of CVD among those with more optimism but this connection could not be explained by the mediating effect of the level of inflammation [31]. In that study, optimism was measured by asking the test subjects what they think about their risk of developing CHD, so the question evaluated self-rated health rather than optimism.

Even if both LOT and LOT-R were thought to be unidimensional scales (i.e. the result of the test was given as a combination of the answers to the pessimistically and optimistically oriented statements), later studies have suggested that they may have two separate independent dimensions, namely optimism and pessimism. Dividing the optimism scaling from pessimism and examining the results separately seems to lead to better prediction of outcomes [32], [33]. In a bipolar univariate model, optimism and pessimism may hide some of each other's results. It has also been suggested that dispositional optimism could be a unidimensional continuum, but LOT-R divides it into two independent subscales, optimism and pessimism [34] and the questions worded negatively might be better at measuring this 
personal trait than the optimistically oriented questions. According to this theory the questions worded positively may not give consistent results, leading to the weak statistical power of the optimism subscale [13].

In our earlier study we demonstrated that in this study group, optimism and pessimism seem to be separate variables [4], a finding that has also been made in many other study groups [35], [36], [37]. In the present study, the two-factor model of optimism and pessimism - i.e. optimism and pessimism being two separate and independent variables instead of one bipolar factor - was confirmed. While the connection between pessimism and CHD appeared to be solid, optimism did not associate with the incidence of CHD.

Optimism and pessimism characterize an individual in ordinary situations. Like other personality traits, their development appears to be influenced by both heritage and environment [38], [39]. Unlike mood, for example, they seem to be stable once they have evolved, and they remain the same in different situations and over time, regardless of the negative or positive incidents [40], [41].

The association between psychosocial factors and CHD seems to be quite confident, and our study endorses the need to continue the research in this area. Our hypothesis of inflammation mediating the connection between pessimism and CHD was confirmed to a marked degree. Finding the other mediating factors between pessimism and CHD could help in understanding CHD, its aetiology and mechanism, which in turn could help in preventing and treating CHD.

The strength of our study is in its design. The study group can be seen as comprehensive one. Ten years is a relatively long time, and the prospective nature of the study makes the results more reliable. The use of a well-known test pattern (LOT-R) in determining optimism and pessimism makes our study more convincing. Separating optimism from pessimism seemed to clarify our results. CRP has a long plasma half-life and relative stability as a frozen sample, which makes it quite easy and reliable to measure [42].

There are a few shortcomings in this study. One of them is that we could use only self-reports 
for some variables, which can lead to biased information. Self-reports were used in the variables concerning life habits (e.g. smoking and the use of alcohol). However, it has been demonstrated that alcohol consumption can be estimated quite accurately using self-reports [43], [44], [45], [46] and while self-reports concerning smoking status are usually not so reliable, they are very useful when the respondents are elderly [47], like the participants in our study. We had access to the Records of Causes of Deaths, and thus we could determine the number of people who died due to $\mathrm{CHD}$, but the prevalence of $\mathrm{CHD}$ at the beginning of the study and the number of new cases of $\mathrm{CHD}$ during the follow-up among those who were alive at the end of the study were based on self-reports. However, self-reports are quite reliable like earlier mentioned, and the numbers concerning $\mathrm{CHD}$ received by self-reports are quite similar to the prevalence and incidence rates of $\mathrm{CHD}$ that can be calculated from the official statistics for the same-aged population in Finland [48], [49].

It is also expected that there were some people with new $\mathrm{CHD}$ among those who died during the follow-up due to some other reason than CHD, and those individuals could not be included in the study. It also seems that poorly functioning and institutionalized persons had a lower participation rate than community-dwelling subjects, which can have an effect on the results [50]. In addition, the level of CRP may have been high for temporary reasons in some cases, which might have lightened our finding. Another possible form of bias is related to the fact that the levels of hs-CRP were analysed in samples that had been frozen for more than 10 years.

Consequently, there is a risk that the absolute levels of hs-CRP could have been affected by having been taken from frozen - rather than fresh - samples. However, it has been found that CRP is relatively stable as a frozen sample [42] and the freezing time was the same for all samples.

\section{Conclusion}


It seems that the previously identified connection between pessimism and the risk of developing $\mathrm{CHD}$ is partially mediated indirectly through the low-grade tissue inflammation as

we hypothesized. While the finding is significant, it means that there also are other biological mediators between pessimism and the risk coronary heart disease.

\section{Declarations}

Ethics approval and consent to participate

The cohort study was approved in 2002 by the Ethics Committee of Päijät-Häme Central

Hospital, which is located in the city of Lahti, and this extension study was approved in 2013

by the Ethics Committee of Pirkanmaa Hospital District (R12013). Written informed consent

was requested and obtained from all cohort participants in 2002.

Consent for publication

Not applicable.

Availability of data and material

The dataset supporting the conclusions of this article is a part of the GOAL (Good Ageing in

Lahti Region) Project and it was collected and is preserved by the Palmenia Centre for

Continuing Education in Lahti, Finland.

Competing interest

The authors declare that they have no competing interests.

Funding

This study was supported with an EVO (special state funding) grant from Päijät-Häme Central

Hospital (expenses of laboratory tests and other data collection) and a grant from Finnish Medical Foundation (Suomen Lääketieteen Säätiö) (expenses of language editing).

Authors' contributions

Authors MP and $\mathrm{JH}$ designed the study. TK, OK and MK participated in the conception of the study. $\mathrm{JH}$ managed and conducted the statistical analyses and interpreted the data. MP wrote the first draft and MP, JH, OK, TK, MK, EL and HS revised it to make the final manuscript. All 
authors have approved the final manuscript.

ACKNOWLEDGEMENTS

We thank all the participants in the GOAL Project.

\section{Abbreviations}

CHD, coronary heart disease; CRP, C-reactive protein; hs-CRP, high-sensitivity C-reactive protein; GOAL, Good Ageing in Lahti region study; BMI, body mass index; HDL, high-density lipoprotein; AUDIT-C, Alcohol Use Disorders Identification Test - Consumption; LOT, Life Orientation Test; LOT-R Life Orientation Test re-evaluated; THL, The National Institute for Health and Welfare.

\section{References}

1. Nichols M, Townsend N, Scarborough P, Rayner M: Cardiovascular disease in Europe epidemiological update 2015. European Heart Journal 2015(36): 2696-705.

2. Rosengren, A, Hawken S, Ôunpuu S, Sliwa K, Zbaid M, Almahmeed WA, Blackett KN, Sitthi-amorn C, Sato $\mathrm{H}$, Yusuf S. Association of psychosocial risk factors with risk of acute myocardial infarction in 11,119 cases and 13,648 controls from 52 countries (the INTERHEART study): case-control study. Lancet 2004;364:953-62.

3. Depression as a risk factor for poor prognosis among patients with acute coronary syndrome: systematic review and recommendations: a scientific statement from the American Heart Association. Circulation 2014;129:1350-69.

4. Pänkäläinen $M$, Kerola $T$, Hintikka J. Pessimism and the risk for coronary heart disease among middle-aged and older Finnish men and women: A ten-year follow-up study. BMC Cardiovascular Disorders. 2015;15:113.

5. Scheier MF, Magovern GJ, Abbott RA, Matthews KA, Owens JF, Lefebvre RC, Carver CS. Dispositional optimism and recovery from coronary artery bypass surgery: The beneficial effects on physical and psychological well-being. J Pers Soc Psychol. 1989;57:1024-40.

6. Anthony EG, Kritz-Silverstein D, Barrett-Connor E: Optimism and Mortality in Older Men and Women: The Rancho Bernardo Study. Journal of Aging Research 2016;1:1-9.

7. Koenig W: High-sensitivity C-reactive protein and atherosclerotic disease: From improved risk prediction to risk-guided therapy. International Journal of Cardiology 2013;168(6):5126-34.

8. Zakai NA, Katz R, Jenny NS, Psaty BM, Reiner AP, Schwartz SM, Cushman M: Inflammation and hemostasis biomarkers and cardiovascular risk in the elderly: The Cardiovascular Health Study. Journal of Thrombosis and Haemostasis 2007;5:1128-35. 
9. Pänkäläinen M, Kerola T, Kampman O, Kauppi M, Hintikka J. Pessimism and risk of death from coronary heart disease among middle-aged and older Finns: an eleven-year follow-up study. BMC Public Health. 2016;16:1124.

10. O’Donovan A, Lin J, Dhabhar FS, Wolkowitz O, Tillie JM, Blackburn E, Epel E: Pessimism correlates with leukocyte telomere shortness and elevated interleukin-6 in post-menopausal women. Brain, Behavior and Immunity 2009;23:446-9.

11. Ikeda A, Schwartz J, Peters JL, Fang S, Spiro III A, Sparrow D, Vokonas P, Kubzansky: Optimism in Relation to Inflammation and Endothelial Dysfunction in Older Men: The VA Normative Study. Psychosomatic Medicine 2011;73:664-71.

12. Rius-Ottenheim N, de Craen AJM, Geleijnse JM, Slagboom PE, Kromhout D, van der Mast RC, Zitman FG, Westendorp RG, Giltay EJ: C-reactive protein haplotypes and dispositional optimism in obese and nonobese elderly subjects. Inflammation Research Inflamm. Res. 2012;61:43-51.

13. Roy B, Diez-Roux AV, Seeman T, Ranjit N, Shea S, Cushman M: Association of Optimism and Pessimism With Inflammation and Hemostasis in the Multi-Ethnic Study of Atherosclerosis (MESA). Psychosomatic Medicine 2010;72:134-40.

14. Brydon L, Walker C, Wawrzyniak AJ, Chart H, Steptoe A: Dispositional optimism and stress-induced changes in immunity and negative mood. Brain, Behavior, and Immunity 2009;23:810-6.

15. Allen JP, Litten RZ, Fertig JB ym. A review of research on the Alcohol Use Disorders Identification Test (AUDIT). Alcohol Clin Exp Res 1997;21:613-9

16. Reinert DF, Allen JP. The Alcohol Use Disorders Identification Test (AUDIT): a review of recent research. Alcohol Clin Exp Res 2002;26:272-9.

17. Bradley KA, DeBenedetti AF, Volk RJ, Williams EC, Frank D, Kivlahan DR. AUDIT-C as a brief screen for alcohol misuse in primary care. Alcohol Clin Exp Res. 2007;31:1208-17.

18. Aalto M, Alho H, Halme JT, Seppä K. AUDIT and its abbreviated versions in detecting heavy and binge drinking in a general population survey. Drug Alcohol Depend. 2009;103:25-29.

19. Scheier MF, Carver CS. Optimism, coping and health: assessment and implications of generalized outcome expectancies. Health Psychol. 1985;4:219-47.

20. Scheier MF, Carver CS, Bridges MW. Distinguishing optimism from neuroticism (and trait anxiety, selfmastery, and self-esteem): a re-evaluation of the Life Orientation Test. J Pers Soc Psychol. 1994;6:1063-78.

21. MacKinnon DP, Dwyer JH. Estimating mediated effects in prevention studies. Eval Rev 1993;17:14458.

22. Baron M, Kenny DA. The moderator-mediator variable distinction in social psychological research: conceptual, strategic and statistical considerations. J Pers Soc Psychol 1986;51:1173-82.

23. Kubzansky LD, Sparrow D, Vokonas P, Kawachi I. Is the glass half empty or half full? A prospective study of optimism and coronary heart disease in the normative aging study. Psychosom Med. 2001;63:910-16. 
24. Giltay EJ, Kamphuis MH, Kalmijn S, Zitman FG, Kromhout D. Dispositional optimism and the risk of cardiovascular death: the Zutphen Elderly Study. Arch Intern Med. 2006;166:431-6.

25. Tindle HA, Chang YF, Kuller LH, Manson JE, Robinson JG, Rosal MC, Siegle GJ, Matthews KA. Optimism, cynical hostility, and incident coronary heart disease and mortality in the Women's Health Initiative. Circulation. 2009;120:656-62.

26. Hansen JD, Shimbo D, Shaffer JA, Hong S, Borda T, Ventura A, Schwartz JE, Harlapur M, Davidson KW. Finding the glass half full? Optimism is protective of 10-year incident CHD in a population-based study: the Canadian Nova Scotia Health Survey. Int J Cardiol. 2010;145:603-4.

27. Steptoe A, O’Donnell K, Badrick E, Kumari M, Marmot M: Neuroendocrine and Inflammatory Factors Associated with Positive Affect in Healthy Men and Women. American Journal of Epidemiology 2008;167(1):96-102.

28. Copeland WE, Shanahan L, Worthman C, Angold C, Costello EJ: Cumulative Depression Episodes Predict Later C-Reactive Protein levels: A Prospective Analysis. Biological Psychiatry 2012;71(1):1521.

29. Liukkonen T, Silvennoinen-Kassinen S, Jokelainen J, Räsänen $P$, Leinonen M, Meyer- Rochow VB, Timonen M: The Association Between C-Reactive Protein Levels and Depression: Results from the Northern Finland 1966 Birth Cohort Study. Biological Psychiatry 2006;60:825-30.

30. Whooley MA, Caska CM, Hendrickson BE, Rourke MA, Ho J, Ali S: Depression and Inflammation in Patients With Coronary Heart Disease: Findings from the Heart and Soul Study. Biol Psychiatry 2007;62:314-20.

31. Gramling R, Heffner KL, Klein WMP, Zajac LE, Roberts M, Eaton CB: Is the association between optimistic cardiovascular risk perceptions and lower rates of cardiovascular disease mortality explained by biomarkers of systemic inflammation or endothelial function? A case-cohort study. BioPsychoSocial Medicine 2010;4:11.

32. Robinson-Whelen S, Kim C, MacCallum RC, Kiecolt-Glaser JK. Distinguishing optimism from pessimism in older adults: is it more important to be optimistic or not to be pessimistic? J Pers Soc Psychol. 1997;6:1345-53.

33. Chang EC, Maydeu-Olivares A, D'Zurilla TJ. Optimism and pessimism as partially independent constructs: Relationship to positive and negative affectivity and physiological well-being. Pers Indiv Differ. 1997;3:433-40.

34. Monzani D, Steca P, Greco A. Brief report: assessing dispositional optimism in adolescence - factor structure and concurrent validity of the Life Orientation Test Revised. J Adolesc. 2014;37:97-101.

35. Herzberg PY, Glaesmer H, Hoyer J. Separating optimism and pessimism: a robust psychometric analysis of the revised Life Orientation Test (LOT-R). Psychol Assessment. 2006;18:433-8.

36. Kubzansky LD, Kubzansky PE, Maselko J. Optimism and pessimism in the context of health: bipolar opposites or separate constructs? Pers Soc Psychol Bull 2004;30:943- 56.

37. Glaesmer H, Rief W, Martin A, Mewes R, Brahler E, Zenger M, Hinz A. Psychometric properties and population-based norms of the Life Orientation Test Revised (LOT-R). Br J Health Psychol. 
2012;17:432-45.

38. Schulman P, Keith D, Seligman MEP. Is optimism heritable (A study of twins). Behav Res Ther. 1993;6:569-74.

39. Mosing MA, Medland SE, McRae A, Landers JG, Wright MJ, Martin NG. Genetic influences on life span and its relationship to personality: a 16-year follow-up study of a sample of aging twins. Psychosom Med. 2012;74:16-22.

40. Billingsley KD, Waehler CA, Hardin SI. Stability of optimism and choice of coping strategy. Percept Mot Skills. 1993;76:91-7.

41. Schou I, Ekeberg O, Sandvik L, Ruland CM. Stability in optimism-pessimism in relation to bad news: a study of women with breast cancer. J Pers Assess. 2005;2:148-54.

42. Yousuf O, Mohanty BD, Martin SS, Joshi PH, Blaha MJ, Nasir K, Blumenthal RS, Budoff MJ: HighSensitivity C-reactive protein and Cardiovascular Disease: A Resolute Belief or an Elusive Link? Journal of American College of Cardiology 2013;62(5):397-408.

43. Sobell LC, Sobell MB. Alcohol Consumption Measures. In: Allen JP, Wilson VB, editors. Assessing Alcohol Problems. A Guide for Clinicians and Researchers, Second Edition. NIH Publication No. 033745; 2003. p.75-99.

44. Bell NS, Williams JO, Senier L, Strowman SR, Amoroso PJ. The Reliability and Validity of the SelfReported Drinking Measures in the Army's Health Risk Appraisal Survey. Alcoholism: Clinical and Experimental Research 2003;27:826-34.

45. Gruenewald PJ, Johnson FW. The Stability and Reliability of Self-Reported Drinking Measures. Journal of Studies on Alcohol. 2006;67:5.

46. Del Boca FK, Darkes J. The validity of self-reports of alcohol consumption: State of the science and challenges for research. Addiction. 2003(98);S2:1-12.

47. Pell JP, Haw S, Cobbe SM Newby DE, Pell ACH, Oldroyd KG, Murdoch DL, Pringle SD, Dunn FG, Maclntyre PD, Gilbert TJ, Fischbacher CM, Borland W. Validity of selfreported smoking status: Comparison of patients admitted to hospital with acute coronary syndrome and the general population. Nicotine and Tobacco Research 2008;10:5.

48. The Social Insurance Institution (KELA). Reimbursement of drug expenses in Finland. 2015. http://raportit.kela.fi/ibi_apps/WFServlet?IBIF_ex=NIT084AL\&YKIELI=E (accessed November 13th, 2018)

49. Statistics Finland. Population in Finland. 2015. http://www.tilastokeskus.fi/tup/suoluk/suoluk_vaesto.html (accessed November 13th, 2018)

50. Nummela O, Sulander T, Helakorpi S, Haapola I, Uutela A, Heinonen H, Valve R, Fogelholm M. Register-based data indicated nonparticipation bias in a health study among aging people. Journal of Clinical Epidemiology 2011;64:1418-25. 